\title{
Common antibody dependent cell mediated cytotoxicity (ADCC) antibody epitopes of HIV-1 CRF01_AE Env and Gag in early HIV-1 infected individuals
}

\author{
Soraya Sangjan, ${ }^{1, a}$ Silawun Ampol, ${ }^{1, a}$ Sutchana Tabprasit, ${ }^{2}$ Navin Horthongkham, ${ }^{1}$ Thippawan Chuenchitra, ${ }^{2}$ Pattama Ekpo, ${ }^{3}$ \\ Wannee Kantakamalakul, ${ }^{1 *}$
}

\begin{abstract}
Background: There have been a few studies aimed at identifying epitopes of ADCC-inducing antibodies when compared to those of neutralizing antibodies and cytotoxic T lymphocytes against a variety of HIV-1 clades.

Objective: To map the common ADCC epitopes of HIV-1 CRF01_AE.

Methods: We screened 65 sera of confirmed early HIV-1 CRF01_AE infected individuals for ADCC antibody against gp120 utilizing an EGFP-CEM-NK ${ }^{\mathrm{r}}$ flow cytometric assay. Sera with high ADCC antibody were then examined against ADCC epitopes using the complete HIV-1 CRF01_AE gp160- and subtype A Gag-overlapping peptide sets which were divided into 7 pools:E1-E7 and 5 pools:G1-G5, respectively. Each positive peptide pool was further investigated for fine ADCC epitope mapping using matrix formats.

Results: Twenty, 25 and 20 sera demonstrated the high-, medium- and low-ADCC antibody activities against gp120, respectively. Interestingly, 11 Env- and 6 Gag-peptides of pools E3, E4, E7 and pools G1, G2, G4 with high ADCC responses were also responded by at least $20 \%, 12 \%$ and 5\%,10\% of medium- and low-ADCC antibody sera, respectively. These eleven common Env ADCC epitopes were localized at C2-V3-C3-V4 regions of gp120 and cytoplasmic tail of gp41 while six common Gag ADCC epitopes were localized at p17-p24-p2 regions.

Conclusions: Although the degree of ADCC antibody responses to the gp120 protein varied from high to low, there were certain consensus Env and Gag peptides that could induce the ADCC antibody responses of 21.54-58.46\% and 23.08$41.54 \%$, respectively of the early infected individuals. This epitope information should be useful as the new antibody-based vaccine immunogens.
\end{abstract}

Keywords: ADCC antibody epitopes; HIV-1 CRF01_AE; Env; Gag; early infection

\section{From:}

Department of Microbiology, Faculty of Medicine Siriraj Hospital, Mahidol University, Bangkok, Thailand

Research Division, Armed Forces Research Institute of Medical Sciences (AFRIMS)-Royal Thai Army, Bangkok, Thailand

Department of Immunology, Faculty of Medicine Siriraj Hospital, Mahidol University, Bangkok, Thailand

\footnotetext{
a Contributed equally to this article.

* Corresponding author:

Wannee Kantakamalakul

Email: wannee.kan@mahidol.ac.th
}

\section{Introduction}

The development of effective HIV-1 vaccines is urgently required for controlling future spread of HIV-1. ${ }^{1}$ Current prophylaxis HIV-1 vaccine trials are based on both arms of immune responses, i.e., humoral and cellular immunity. However, each arm has not yet been successful. ${ }^{2}$ Antibody dependent cell mediated cytotoxicity (ADCC) is a cytolytic mechanism of natural killer (NK) cells against virus-infected cells by combining of the innate and adaptive immunity. The mechanism of ADCC can be stimulated by the interaction of specific antibody bound to HIV-1 antigens on the infected cells and Fc receptor CD16 (Fc $\gamma$ RIIIa) expressed on the surface of NK cells. Activation of NK cells lead to lysis of target cells. ${ }^{3}$ 
ADCC responses have been reported to correlate with the control or limit viremia during acute HIV-1 infection and help to slow the progression of disease in both HIV-1 infected individuals and SIV infected macaques. ${ }^{4,5}$ Of the six HIV-1 efficacy trials, the RV144 prime-boost regimen phase III trial has provided evidence of vaccine-induced $31.2 \%$ protection. ${ }^{2}$ Vaccinees who showed significantly low risk of HIV-1 infection demonstrated the high level of ADCC antibody responses. ${ }^{6}$

In the clinical course of HIV-1 infection, the acute phase of infection reveals an initial high peak of plasma viremia and decreased number of $\mathrm{CD}^{+}{ }^{+} \mathrm{T}$ lymphocytes. ${ }^{7}$ In addition, expansion of inefficient HIV-1-specific $\mathrm{CD}^{+} \mathrm{T}$ cells during acute infection has recently been reported. ${ }^{8}$ Finding of the early effective immune responses against transmitted virus in acute HIV-1 infection may give a chance to control initial viremia, prolong HIV-1 disease progression, decrease immune cell damage and prevent transmission. ${ }^{9}$ Identification of the common epitopes of HIV-1 that could respond to ADCC antibody of sera with low-, medium- or high-ADCC against envelope protein at the early phase would be an important new information that can be utilized for vaccine development. Here we have identified common ADCC antibody epitopes of Env and Gag of HIV-1 CRF01_AE using sera of confirmed early HIV-1 infected individuals.

\section{Methods \\ Volunteer samples}

All sera samples from young Thai men who were enrolled to the conscripts during year 2001-2013 were obtained with written informed consents following approval from Institutional Review Board (IRB) of Royal Thai Army Medical Department (Code: S034b/57) and IRB of the Faculty of Medicine Siriraj Hospital (COA: Si609/2014) prior to initiation of this study. The sera samples obtained had no individual identifiers. These sera were confirmed as early HIV-1 infection by using the Aware ${ }^{\mathrm{Tm}}$ BED $^{\text {TM }}$ EIA HIV-1 Incidence Test (Calypte Co., Portland, OR, USA).

\section{Cell line}

The NK cell resistant, EGFP-CEM-NK ${ }^{\mathrm{r}}$ cells were cultured and prepared for the assay as previously described. ${ }^{10}$

\section{Peptides}

The gp120 of HIV-1 CRF01_AE CM243 (Protein Sciences, Meriden, CT, USA) was used to pulse the EGFP-CEM-NK ${ }^{\mathrm{r}}$ cells. In addition, the complete peptide set based on the HIV-1 CRF01_AE Env TH023/CM240 sequence consists of 168 peptides (122 peptides of TH023 gp120 and 46 peptides of TH023/CM240 gp41) each containing 15 amino acids (aa) in length, overlapping by 11 aa. The 143 peptides of TH023 were kindly provided by the Natural and Medical Sciences Institute (University of TÜbingen, Germany) and 25 peptides of CM240 were commercially synthesized (GenScript, Piscataway, NJ, USA). These Env peptides were divided into seven pools:E1-E7, each containing 24 peptides. To further identify the reactive peptide, each informative peptide pool was again divided into ten small pools according to the 5 by 5 matrix formats. Moreover, Gag peptide set of $\mathrm{HIV}-1$ subtype A sequence consisting of 49 peptides each containing 20 aa in length, overlapping by 10 aa was kindly provided by the National Institutes of Health (NIH) AIDS reagent repository (catalog \#3991). These Gag peptides were divided into five pools:G1-G5, each containing 9-10 peptides. Each pool was again divided into three small pools as 3 by 3 matrix formats. Each peptide pool was also used to pulse the EGFP-CEM-NK ${ }^{\mathrm{r}}$ cells.

\section{Preparation of sera}

All sera were from individuals infected with HIV-1 CRF01 _AE as determined by $\mathrm{C} 2-\mathrm{V} 4$ nucleotide sequencing as described elsewhere. ${ }^{11}$ A HIV-1 sero-negative pooled serum and a sero-positive serum with high ADCC antibody activity were used as controls with each assay. All sera were inactivated at $56^{\circ} \mathrm{C}$ for $30 \mathrm{~min}$. prior to use and used at dilutions of 1:250, $1: 2,500$ and $1: 25,000$.

\section{Target cells}

The gp120- or peptide pool-pulsed EGFP-CEM-NK ${ }^{\mathrm{r}}$ target cells were prepared by the addition of either $0.1 \mu \mathrm{g}$ gp120 of HIV-1 CRF01_AE CM243 or $1 \mu \mathrm{g}$ of each peptide pool to $1 \times$ $10^{5}$ target cells. The peptide and target cells were incubated for $1 \mathrm{~h}$ at room temperature. The gp120 pulsed cells were washed three times with phosphate buffered saline. The target cells were then re-suspended in growth medium containing RPMI 1640 (Gibco, Grand Island, NY) supplemented with $2 \mathrm{mM}$ l-glutamine, $100 \mu \mathrm{g} / \mathrm{ml}$ streptomycin, $100 \mathrm{IU} / \mathrm{ml}$ penicillin, and $10 \%$ heat-inactivated fetal calf serum (Gibco) at a concentration of $1 \times 10^{5}$ cells $/ \mathrm{ml}$.

\section{Effector cells}

Cryopreserved peripheral blood mononuclear cells (PBMC) were prepared from leukopaks of a single HIV-1 seronegative blood donor as previously described. ${ }^{10}$ Cells were later thawed and overlaid overnight at $1 \times 10^{6}$ cells $/ \mathrm{ml}$ in growth medium at $37{ }^{\circ} \mathrm{C}$ with $5 \% \mathrm{CO} 2$. The cells were then re-suspended in growth media at a concentration of $2.5 \times 10^{6}$ cells $/ \mathrm{ml}$ and used as effector cells.

\section{EGFP-ADCC flow cytometric assay}

The EGFP-ADCC flow cytometric assay was based on a method previously described. ${ }^{10}$ Lysis of target cells by ADCC activity was measured and analyzed with a FACScan flow cytometer (Becton Dickinson Biosciences $\{B D B\}$, San Jose, CA, USA). The actual percent lysis of target cells at each serum dilution was calculated as previously reported. ${ }^{10}$ The cut-off for positive results using gp120- and peptide pool-pulsed target cells are $7.21 \%$ lysis and $5.46 \%$ lysis, respectively. ${ }^{12}$

\section{Results \\ Screening for high ADCC antibody activity against gp120 pulsed target cells}

Sixty five confirmed early HIV-1 CRF01_AE infected sera were investigated for ADCC antibody activity against gp120 pulsed target cells. The percent lysis of target cells ranged from $9.15 \%$ to $56.12 \%$ with mean and SD values of 24.08 and 10.72 , respectively. Twenty, 25 and 20 sera demonstrated the high $(>29.44 \%$ target cell lysis, $>$ mean $+0.5 \mathrm{SD})$, medium 
(29.44-18.72\% lysis, mean $\pm 0.5 \mathrm{SD})$ and low ( $<18.72 \%$ lysis, $<$ mean-0.5SD) ADCC antibody activities, respectively.

\section{Identification of HIV-1 CRF01_AE gp160-and Gag-epitopes that are the target of $A D C C$ reactive antibodies}

Twenty sera with relatively high ADCC antibody activity were further examined against each of the seven peptide pools:E1-E7 of the HIV-1 CRF01_AE Env peptide set and each of the five peptide pools:G1-G5 of HIV-1 subtype A Gag formulated as described in the methods section. These 20 sera demonstrated positive ADCC antibody responses against a number of Env peptide pools while 18 sera responded against Gag peptide pools as shown in Table 1. For Env peptide pools, whereas sixteen $(80 \%)$, fourteen $(70 \%)$, and twelve $(60 \%)$ sera demonstrated significantly higher frequency of ADCC responses against pools E7, E3 and E4, respectively, six to ten $(30-50 \%)$ of these sera showed significant but somewhat lower frequency of ADCC responses to peptide pools E2, E1, E6 and E5. Moreover, 9/20 (45\%) of tested sera demonstrated the responses to all three peptide pools: E3, E4, E7. In addition, all tested sera responded to at least one of these three peptide pools. Thus, a 5 by 5 matrix of each of the 3 peptide pools E3, E4 and E7 was selected to perform the fine epitope mapping of ADCC responses. The potential ADCC antibody epitopes were identified by verifying the common peptides from this matrix. The common peptides within pools E3, E4 and E7 that responded to ADCC activity of each of the 20 tested sera are shown in Table 2. Twelve potential ADCC antibody epitopes with $\geq 50 \%$ responses of all tested sera in each pool were identified. For the parent E3 peptide pool, 9/14 (64.29\%) and 7/14 (50\%) sera showed ADCC activity against peptides (78, 83 ) and 71, respectively. For the parent E4 pool, 8/12 (66.67\%), $7 / 12(58.33 \%)$ and $6 / 12(50 \%)$ of sera showed ADCC activity against peptides $87,(84,85,95,97)$ and $(89,92)$, respectively. Moreover, 8/16 (50.00\%) sera demonstrated ADCC activity against peptides 190 and 191 from the parent E7 pool.

For Gag peptide pools, whereas fourteen (70\%), twelve $(60 \%)$ and ten $(50 \%)$ sera demonstrated significantly higher frequency of ADCC antibody responses against pools G4, G2 and $\mathrm{G1}$, respectively, three to seven (15-35\%) of these sera showed significant but somewhat lower frequency of ADCC responses to pools G3 and G5 (Table 1). In addition, 6/20 $(30 \%)$ of tested sera recognized all three peptide pools: G1, G2, G4. However, two sera (10\%) did not respond to any pool of Gag peptide. Thus, a 3 by 3 matrix of each of the 3 peptide pools G1, G2 and G4 was selected to perform the fine epitope mapping of ADCC responses. The common peptides within pools G1, G2 and G4 that responded to ADCC activity of each of the 18 sera tested are shown in Table 3. Six potential ADCC antibody epitopes with $\geq 50 \%$ responses of all tested sera in each pool

Table 1. Identification of peptide pools that are the targets of antibody dependent cell mediated cytotoxicity (ADCC) antibody responses in high ADCC antibody activity sera.

\begin{tabular}{|c|c|c|c|c|c|c|c|c|c|c|c|c|c|}
\hline \multirow{2}{*}{$\begin{array}{c}\text { Serum No. } \\
11\end{array}$} & Obtained year & \multicolumn{5}{|c|}{$\begin{array}{l}\text { \# Env peptide pools (E1-E7) } \\
\text { response to ADCC antibody }\end{array}$} & & & \multicolumn{4}{|c|}{$\begin{array}{l}\text { \# Gag peptide pools (G1-G5) } \\
\text { response to ADCC antibody }\end{array}$} & \\
\hline & 2001 & & & 3 & & & & & & & - & & \\
\hline 4 & 2007 & 1 & 2 & & & 5 & 6 & 7 & 1 & & & 4 & \\
\hline 14 & 2007 & 1 & 2 & & & & & 7 & & 2 & & 4 & 5 \\
\hline 10 & 2008 & 1 & & & & & 6 & 7 & & & & 4 & \\
\hline 15 & 2009 & 1 & & 3 & 4 & 5 & & 7 & & 2 & 3 & 4 & \\
\hline 3 & 2011 & & & 3 & & & 6 & & & & - & & \\
\hline 11 & 2011 & 1 & 2 & 3 & & 5 & & 7 & 1 & 2 & & 4 & 5 \\
\hline 15 & 2011 & & & 3 & 4 & & & 7 & & 2 & & & 5 \\
\hline 16 & 2011 & & & 3 & 4 & & & 7 & 1 & 2 & & & 5 \\
\hline 4 & 2012 & & 2 & & 4 & 5 & & 7 & 1 & 2 & 3 & 4 & 5 \\
\hline 5 & 2012 & & & 3 & 4 & 5 & 6 & 7 & & 2 & & & 5 \\
\hline 7 & 2012 & & & 3 & 4 & 5 & 6 & 7 & 1 & 2 & & 4 & \\
\hline 9 & 2012 & & & & 4 & & & 7 & 1 & 2 & 3 & & \\
\hline 12 & 2012 & & & 3 & & 5 & & & 1 & 2 & & 4 & \\
\hline 17 & 2012 & 1 & & 3 & 4 & & 6 & 7 & 1 & 2 & & 4 & \\
\hline 5 & 2013 & & & 3 & & & & 7 & & & & 4 & \\
\hline 6 & 2013 & & 2 & 3 & 4 & 5 & 6 & 7 & & & & 4 & \\
\hline 7 & 2013 & & 2 & & 4 & 5 & 6 & & & & & 4 & 5 \\
\hline 8 & 2013 & 1 & & 3 & 4 & 5 & & 7 & 1 & 2 & & 4 & \\
\hline 9 & 2013 & & & 3 & 4 & & 6 & 7 & 1 & & & 4 & \\
\hline Total & & 7 & 6 & 14 & 12 & 10 & 9 & 16 & 10 & 12 & 3 & 14 & 7 \\
\hline
\end{tabular}

High ADCC antibody activity against HIV-1 gp120 pulsed target cells of twenty HIV-1 seropositive sera were analyzed for their individual responses to target cells pulsing with either each of 7 peptide pools (E1-E7) comprising the complete HIV-1 subtype CRF01_AE TH023/CM240 gp160 peptide set consisting of 168 peptides 15 amino acids in length or each of 5 peptide pools (G1-G5) comprising the complete HIV-1 subtype A Gag peptide set consisting of 49 peptides 20 amino acids in length. Each pool of Env- and Gag-peptides contains 24 and 9-10 peptides, respectively. Sera years of HIV-1 infection are also shown. 
Table 2. Peptide mapping of high ADCC antibody sera against Env peptide pools E3, E4 and E7.

\begin{tabular}{|c|c|c|c|c|c|}
\hline \multicolumn{2}{|c|}{ Serum } & \multicolumn{3}{|c|}{ Single peptide number of Env pool responses to ADCC antibody } & \multirow{2}{*}{$\begin{array}{c}\text { Total } \\
\text { peptide } \\
\text { responses }\end{array}$} \\
\hline No. & $\begin{array}{l}\text { Obtained } \\
\text { year }\end{array}$ & Env pool 3 (E3) & Env pool $4(\mathrm{E} 4)$ & Env pool 7 (E7) & \\
\hline 11 & 2001 & 78,83 & - & - & 2 \\
\hline 4 & 2007 & - & - & $188,190,191$ & 3 \\
\hline 14 & 2007 & - & - & $176,181,186$ & 3 \\
\hline 10 & 2008 & - & - & $175,176,180,181,185,186,190,191$ & 8 \\
\hline 15 & 2009 & $62,65,66,83$ & $87,88,92,93,97,98$ & $177,179,186-189,190,191$ & 18 \\
\hline 3 & 2011 & 78 & - & - & 1 \\
\hline 11 & 2011 & $70,71,75,77,78,82,83$ & - & 181,191 & 9 \\
\hline 15 & 2011 & $\begin{array}{c}63,65,66,68,70,71,75,77,78,80,81 \\
\mathbf{8 3}\end{array}$ & $90, \mathbf{9 2}, 94, \mathbf{9 5}, \mathbf{9 7}, 99$ & 179,180 & 20 \\
\hline 16 & 2011 & $70,71,77,78,82,83$ & $\begin{array}{c}\mathbf{8 4}, \mathbf{8 5}, 86,87,88,90,91, \mathbf{9 2}, 93, \mathbf{9 5}, 96 \\
\mathbf{9 7}, 98\end{array}$ & $178-180,188,189,190$ & 25 \\
\hline 4 & 2012 & - & $91, \mathbf{9 2}, 96, \mathbf{9 7}, 101,102$ & $177,178,181,187,188,191$ & 12 \\
\hline 5 & 2012 & $56,57,61,62,66,67,71,74,78,79,83$ & $86,87,89$ & $168,173,178,180,188,190$ & 20 \\
\hline 7 & 2012 & $\begin{array}{c}62,65,66,67,70,71,74,77,78,79,82 \\
\mathbf{8 3}\end{array}$ & $84,85,86,87,88$ & $168-170,173-175,183-185$ & 26 \\
\hline 9 & 2012 & - & $84,85,87,89$ & $172-175,187-189,190$ & 12 \\
\hline 12 & 2012 & 70,71 & - & - & 2 \\
\hline 17 & 2012 & $56-59,62-64,67-69,71$ & $\mathbf{8 4}, \mathbf{8 5}, \mathbf{8 7}, \mathbf{8 9}, \mathbf{9 5}, \mathbf{9 7}, 99,100,102,104$ & 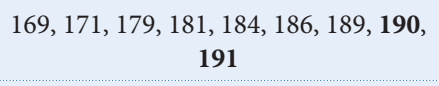 & 29 \\
\hline 5 & 2013 & 78 & - & 191 & 2 \\
\hline 6 & 2013 & $56,57,67,79$ & $87,90,92,95,97$ & $167-169,171,182-184,186$ & 17 \\
\hline 7 & 2013 & - & $\mathbf{8 4}, \mathbf{8 5}, 86, \mathbf{8 9}, \mathbf{9 5}, 96,99,105,106,109$ & - & 10 \\
\hline 8 & 2013 & $71,74,77,78,79,82,83$ & $\begin{array}{c}\mathbf{8 4}, \mathbf{8 5}, 88, \mathbf{8 9}, \mathbf{9 0}, 93,94, \mathbf{9 5}, 98-100 \\
103,104\end{array}$ & $169,170,174,175$ & 24 \\
\hline 9 & 2013 & $63,66,80,83$ & $\begin{array}{c}\mathbf{8 4}, \mathbf{8 5}, \mathbf{8 7}, \mathbf{8 9}, 90, \mathbf{9 2}, 94, \mathbf{9 5}, \mathbf{9 7}, \mathbf{9 9}, 100 \\
102,104\end{array}$ & $\begin{array}{c}167,169-172,174-177,179-182,184- \\
187,189,190,191\end{array}$ & 37 \\
\hline
\end{tabular}

The peptide epitopes that showed $\geq 50 \%$ of ADCC antibody responses of all tested sera against each pool are shown in bold.

Table 3. Peptide mapping of high ADCC antibody sera against Gag peptide pools G1, G2, and G4.

\begin{tabular}{|c|c|c|c|c|c|}
\hline \multicolumn{2}{|c|}{ Serum } & \multicolumn{3}{|c|}{ Single peptide number of Gag pool responses to ADCC antibody } & \multirow{2}{*}{$\begin{array}{c}\text { Total } \\
\text { peptide } \\
\text { responses }\end{array}$} \\
\hline No. & $\begin{array}{c}\text { Obtained } \\
\text { year }\end{array}$ & Gag pool 1 (G1) & Gag pool 2 (G2) & Gag pool 4 (G4) & \\
\hline 4 & 2007 & 3778 & - & $3797-8,3803-4,3806$ & 6 \\
\hline 14 & 2007 & - & 3789,3790 & $3798-9,3804-5$ & 6 \\
\hline 10 & 2008 & - & - & $3798-9,3801,3802,3804-5$ & 6 \\
\hline 15 & 2009 & - & $3784,3789,3790,3742$ & 3800,3801 & 6 \\
\hline 11 & 2011 & 3775 & 3784,3790 & 3800,3802 & 5 \\
\hline 15 & 2011 & - & 3784,3790 & - & 2 \\
\hline 16 & 2011 & 3776,3779 & $3789,3790,3742$ & - & 5 \\
\hline 4 & 2012 & $3778,3779,3780$ & $3788,3789,3790$ & $3800,3802,3803$ & 9 \\
\hline 5 & 2012 & - & 3788,3789 & - & 2 \\
\hline 7 & 2012 & 3776,3779 & 3786,3789 & 3800,3803 & 6 \\
\hline 9 & 2012 & 3776,3779 & $3784,3789,3790,3742$ & - & 6 \\
\hline 12 & 2012 & 3776,3779 & $3784,3786-7,3789,3790,3742$ & $3797, \mathbf{3 8 0 0}, 3806$ & 11 \\
\hline 17 & 2012 & $3775,3776,3777-8,3779,3780$ & $3782-7,3742$ & 3803 & 14 \\
\hline 5 & 2013 & - & - & 3800,3802 & 2 \\
\hline 6 & 2013 & - & - & $3797,3799, \mathbf{3 8 0 0}, \mathbf{3 8 0 2}, 3806$ & 5 \\
\hline
\end{tabular}

The peptide epitopes that showed $\geq 50 \%$ of ADCC antibody responses of all tested sera against each pool are shown in bold. 
Table 3. (Continued) Peptide mapping of high ADCC antibody sera against Gag peptide pools G1, G2, and G4.

\begin{tabular}{|c|c|c|c|c|c|}
\hline \multicolumn{2}{|c|}{ Serum } & \multicolumn{3}{|c|}{ Single peptide number of Gag pool responses to ADCC antibody } & \multirow{2}{*}{$\begin{array}{c}\text { Total } \\
\text { peptide } \\
\text { response }\end{array}$} \\
\hline No. & $\begin{array}{c}\text { Obtained } \\
\text { year }\end{array}$ & Gag pool 1 (G1) & Gag pool 2 (G2) & Gag pool 4 (G4) & \\
\hline 7 & 2013 & - & - & 3800 & 1 \\
\hline 8 & 2013 & $3772-5,3776,3777,3781$ & $3782-8,3789,3790,3742$ & 3802 & 18 \\
\hline 9 & 2013 & $3775,3776,3777-8,3779,3780$ & - & 3801,3802 & 8 \\
\hline
\end{tabular}

The peptide epitopes that showed $\geq 50 \%$ of ADCC antibody responses of all tested sera against each pool are shown in bold.

Table 4. Sequences of potential ADCC antibody epitopes of HIV-1 CRF01_AE Env TH023/CM240

\begin{tabular}{|c|c|c|c|c|c|c|c|}
\hline \multirow{2}{*}{$\begin{array}{l}\text { Peptide } \\
\text { Pool - No. }\end{array}$} & \multirow{2}{*}{$\begin{array}{c}\text { Potential ADCC Ab } \\
\text { epitopes of HIV-1 CRF01_ } \\
\text { AE gp160 }\end{array}$} & \multirow{2}{*}{$\begin{array}{l}\text { Amino } \\
\text { acid \# }\end{array}$} & \multicolumn{3}{|c|}{ Number of sera respond to ADCC epitopes of group } & \multirow{2}{*}{$\begin{array}{l}\text { Total sera } \\
\text { responses } \\
(\%)\end{array}$} & \multirow{2}{*}{$\begin{array}{l}\text { Glycoprotein } \\
\text { location }\end{array}$} \\
\hline & & & $\begin{array}{c}\text { High responses } \\
(\%)\end{array}$ & $\begin{array}{c}\text { Medium responses } \\
(\%)\end{array}$ & $\begin{array}{c}\text { Low responses } \\
(\%)\end{array}$ & & \\
\hline $3-71$ & TNNAK TIIVH LNKSV & $280-294$ & $8 / 20(40)$ & $7 / 25(28)$ & $3 / 20(15)$ & $18 / 65(27.69)$ & gp120 (C2) \\
\hline $3-78$ & SINIG PGQVF YRTGD & $308-322$ & $9 / 20(45)$ & $18 / 25(72)$ & $11 / 20(55)$ & $38 / 65(58.46)$ & gp120 (V3) \\
\hline $3-83$ & RKAYC EINGT KWNEV & $328-342$ & $9 / 20(45)$ & $6 / 25(24)$ & $2 / 20(10)$ & $17 / 65(26.15)$ & gp120 (V3-C3)* \\
\hline $4-84$ & CEING TKWNE VLKKV & $332-346$ & $7 / 20(35)$ & $6 / 25(24)$ & $9 / 20(45)$ & $22 / 65(33.85)$ & gp120 (C3) \\
\hline $4-85$ & GTKWN EVLKK VTKKL & $336-350$ & $7 / 20(35)$ & $11 / 25(44)$ & $10 / 20(50)$ & $28 / 65(43.08)$ & gp120 (C3) \\
\hline $4-87$ & KKVTK KLKEH FNNKT & $344-358$ & $8 / 20(40)$ & $7 / 25(28)$ & $6 / 20(30)$ & $21 / 65(32.31)$ & gp120 (C3) \\
\hline $4-89$ & EHFNN KTIIF QPPSG & $352-366$ & $6 / 20(30)$ & $7 / 25(28)$ & $11 / 20(55)$ & $23 / 65(35.39)$ & gp120 (C3) \\
\hline $4-92$ & PSGGD LEITM HHFNC & $364-378$ & $6 / 20(30)$ & $11 / 25(44)$ & $15 / 20(75)$ & $32 / 65(49.23)$ & gp120 (C3) \\
\hline $4-95$ & FNCRG EFFYC NTTRL & $376-390$ & $7 / 20(35)$ & $8 / 25(32)$ & $2 / 20(10)$ & $17 / 65(26.15)$ & gp120 (C3-V4)** \\
\hline $4-97$ & YCNTT RLFNN TCMEN & $384-398$ & $7 / 20(35)$ & $0 / 25(0)$ & $0 / 20(0)$ & $7 / 65(10.77)$ & gp120 (V4) \\
\hline $7-190$ & LSFQT PSHHQ REPDR & $708-722$ & $8 / 20(40)$ & $5 / 25(20)$ & $1 / 20(5)$ & $14 / 65(21.54)$ & gp41 (CT) \\
\hline $7-191$ & TPSHH QREPD RPEGI & $712-726$ & $8 / 20(40)$ & $5 / 25(20)$ & $5 / 20(25)$ & $18 / 65(27.69)$ & gp41 (CT) \\
\hline
\end{tabular}

$\mathrm{C}=$ constant region; $\mathrm{V}=$ variable region; $\mathrm{CT}=$ cytoplasmic tail

${ }^{\star} \mathrm{V} 3$ (aa 328-331) - C3 (aa 332-342); ${ }^{\star *} \mathrm{C} 3$ (aa 376-384) - V4 (aa 385-390)

Table 5. Sequences of potential ADCC antibody epitopes of HIV-1 CRF01_AE Gag

\begin{tabular}{|c|c|c|c|c|c|c|c|}
\hline \multirow{2}{*}{$\begin{array}{l}\text { Peptide } \\
\text { Pool - No. }\end{array}$} & \multirow{2}{*}{$\begin{array}{c}\text { Potential ADCC Ab } \\
\text { epitopes of HIV-1 } \\
\text { CRF01_AE Gag }\end{array}$} & \multirow{2}{*}{$\begin{array}{l}\text { Amino } \\
\text { acid \# }\end{array}$} & \multicolumn{3}{|c|}{ Number of sera respond to ADCC epitopes of group } & \multirow{2}{*}{$\begin{array}{c}\text { Total sera } \\
\text { responses } \\
(\%)\end{array}$} & \multirow{2}{*}{$\begin{array}{l}\text { Protein } \\
\text { location }\end{array}$} \\
\hline & & & $\begin{array}{c}\text { High responses } \\
(\%)\end{array}$ & $\begin{array}{c}\text { Medium responses } \\
(\%)\end{array}$ & $\begin{array}{c}\text { Low responses } \\
(\%)\end{array}$ & & \\
\hline $1-3776$ & LERFA LNPSL LETTE GCQQI & $41-60$ & $7 / 20(35)$ & $6 / 25(24)$ & $2 / 20(10)$ & $15 / 65(23.08)$ & p17 \\
\hline $1-3779$ & GTEEL RSLYN TVATL YCVHQ & $71-90$ & $7 / 20(35)$ & $8 / 25(32)$ & $7 / 20(35)$ & $22 / 65(33.85)$ & p17 \\
\hline $2-3789$ & MFSAL SEGAT PQDLN MMLNI & $171-190$ & $9 / 20(45)$ & $3 / 25(12)$ & $6 / 20(30)$ & $18 / 65(27.69)$ & $\mathrm{p} 24$ \\
\hline $2-3790$ & PQDLN MMLNI VGGHQ AAMQM & $181-200$ & $9 / 20(45)$ & $5 / 25(20)$ & $7 / 20(35)$ & $21 / 65(32.31)$ & $\mathrm{p} 24$ \\
\hline $4-3800$ & CKSIL RALGA GATLE EMMTA & $330-350$ & $6 / 20(30)$ & $8 / 25(32)$ & $9 / 20(45)$ & $23 / 65(35.39)$ & $\mathrm{p} 24$ \\
\hline $4-3802$ & CQGVG GPGHK ARVLA EAMSQV & $350-370$ & $6 / 20(30)$ & $13 / 25(52)$ & $8 / 20(40)$ & $27 / 65(41.54)$ & $\mathrm{p} 24-\mathrm{p} 2{ }^{*}$ \\
\hline
\end{tabular}

p17 = MA (matrix); p24 = CA (capsid)

${ }^{*}$ p24 (aa 350-363) - p2 (aa 364-370)

were identified. For the parent G1 peptide pool, 7/10 (70.00\%) sera showed ADCC activity against peptides 3776 and 3779. For the parent G2 and G4 pools, 9/12 (75.00\%) and 7/14 (50.00\%) of the sera showed ADCC activity against peptides $(3789,3790)$ and $(3800,3802)$, respectively.

The responses of medium- and low-ADCC antibody sera against the common ADCC antibody epitopes of HIV-1 CRF01_AE Env and Gag that were identified in high ADCC antibody sera

Twenty five medium- and 20 low-ADCC antibody sera were examined for their responses to the 12 and 6 potential common
ADCC antibody epitopes of HIV-1 Env and Gag, respectively. For Env protein, the range of 5/25 (20\%) - 18/25 (72\%) and 1/20 (5\%) - 15/20 (75\%) of medium- and low-ADCC antibody sera, respectively demonstrated the responses to 11 common ADCC epitopes (peptides $71,78,83,84,85,87,89,92,95,190,191$ ); i.e., except peptide 97 (Table 4). The overall responses of 65 tested sera against these peptides were $>20 \%$, i.e., $21.54 \%-58.46 \%$. These 11 common epitopes located within the C2, V3, C3 and V4 of gp120 and the cytoplasmic tail (CT) of gp41 region.

For Gag protein, the range of $3 / 25(12 \%)-13 / 25$ (52\%) and $2 / 20(10 \%)-9 / 20(45 \%)$ of medium- and low-ADCC antibody sera, respectively, demonstrated the responses to 6 common 
ADCC epitopes (peptides 3776, 3779, 3789, 3790, 3800, 3802) (Table 5). The overall responses of 65 tested sera against these peptides were $>20 \%$, i.e., $23.08 \%-41.54 \%$. These 6 common epitopes are localized within the p17, p24 and p2 regions of Gag protein.

\section{Discussion}

In this study, sixty five sera of young Thai men who enrolled to the conscripts were confirmed as sera from early HIV-1 CRF01_AE infected individuals using the Aware ${ }^{\mathrm{Tm}}$ BED $^{\mathrm{m}}$ EIA HIV-1 Incidence Test (data not shown). Estimation of the mean duration of recent infection (MDRI) was 198.4 days for BED. ${ }^{13}$ All sera were screened for high-, medium- and low-ADCC antibody activity against gp120 pulsed target cells utilizing an EGFP-CEM-NK ${ }^{\mathrm{r}}$ flow cytometric assay. The gp120 was used instead of gp160 because only HIV-1 CRF01_AE gp120 is commercially available. Our assay measures the number of target cells that are killed. ${ }^{10}$

Identification of potential ADCC antibody epitopes using a matrix format led to the finding that the spectrum of peptide specific reactivity varied for each serum tested. All tested sera showed reactivity against a total of 1-37, and 1-18 peptides for Env and Gag proteins, respectively (Tables 2, 3). Studies on Env protein further showed that three epitopes (peptides 71 , 78,83 ) of pool E3, seven epitopes (peptides 84, 85, 87, 89, 92, 95,97 ) of pool E4 and two epitopes (peptides 190, 191) of pool E7 were identified as being targets of ADCC antibodies from at least $50.00 \%$ of the tested sera (Table 2). Interestingly, all these potential epitopes except peptide 97 could be able to gain the responses from sera of medium- and low-ADCC activities for at least $20 \%$ and $5 \%$, respectively which made the overall total responses to the range of $21.54-58.46 \%$ (Table 4 ). The aa sequences of the 12 potential ADCC epitopes of HIV-1 CRF01_ AE gp160 are also shown in Table 4. The common peptides 71, 78 , and 83 are localized within the $\mathrm{C} 2, \mathrm{~V} 3$, and $\mathrm{V} 3-\mathrm{C} 3$ regions of gp120, respectively while the common peptides $(84,85,87$, 89, 92), 95 and 97 are localized within the C3, C3-V4 and V4 of gp120, respectively (Figure 1). In addition, the common peptides 190 and 191 are in the cytoplasmic tail region of gp41. Kijak et al. studied the molecular evolution of the HIV-1 epidemic among volunteers of RV144 vaccine trial from 2003 to $2009 .{ }^{14}$ They found that CRF01_AE strains were $31 \%$ more diverse than the ones from the 1990s Thai epidemic. Thus, HIV-1 CRF01_AE strains that infected individuals in our study should also be diverse since the sera were obtained during 2001-2013. Interestingly, sera from these individuals could be able to demonstrate ADCC antibody responses to these common potent epitopes. This indicates that these ADCC epitopes were quite conserved and immunodominant.

Moreover, peptides 78, 85 and 92 showed the responses to ADCC activity at a larger number of sera of medium- and low-ADCC response groups than those of a high-ADCC response group, i.e., (72\%, 55\% vs $45 \%)$, (44\%, 50\% vs 35\%), (44\%, 75\% vs 30\%), respectively. This revealed the importance of these peptide sequences as the prominent ADCC epitopes for induction of ADCC responses against Env peptides of early HIV-1 infected individuals, i.e., 58.46\%, 43.08\% and $49.23 \%$, respectively, of total 65 tested sera (Table 4).

Kulkarni et al. reported that 5 out of 10 Indian long-term non-progressors (LTNPs) demonstrated ADCC activity against the target epitopes in Env-C V3 region (aa 288-330: LNESVEI VCTRPNNNTRKSIRIGPGQTGDIIGDIRQAHC). ${ }^{15}$ They proposed the potential role of this anti-V3 ADCC response in viral control which may contribute to the slower disease progressors. Their epitope sequences included our full epitope peptide 78 (aa 308-322: SINIGPGQVFYRTGD) and partial of epitope peptide 71 (aa 290-294:...LNKSV). The V3 region is one of the most immunogenic epitopes in the envelope which the V3 crown composed of the highly conserved aa I307, I309 and F317 that can induce specific antibody in $>90 \%$ of HIV infected individuals. ${ }^{16,17}$ V3-specific Abs from RV144
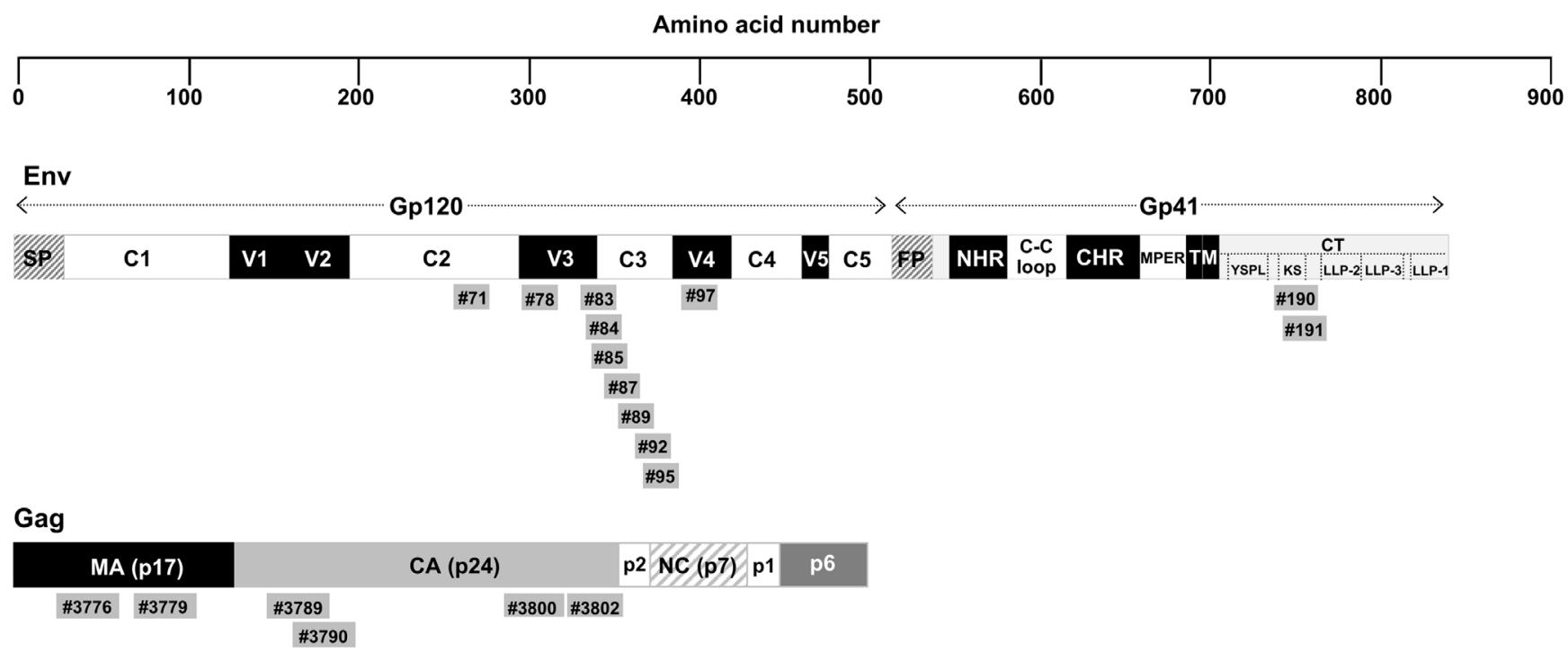

Figure 1. Epitope distribution across the Env gp160 and Gag of HIV-1. ADCC antibody epitopes of HIV-1 CRF01_AE identified in this study are shown. The epitope sizes are not drawn to scale and the amino acid locations of the epitopes are aligned as close as possible with the true alignment. $\mathrm{C}=$ constant region; $\mathrm{V}=$ variable region; $\mathrm{CT}=$ cytoplasmic tail; $\mathrm{KS}=\mathrm{Kennedy}$ sequence; $\mathrm{MA}=$ matrix; $\mathrm{CA}=$ capsid 
vaccinees were shown to capture infectious virions. ${ }^{18}$ Moreover, Montefiori et al. demonstrated the high Nt antibody activity against V3 peptide of HIV-1 CRF01_AE TH023 (aa 302-326: SNNTRTSINIGPGQVFYRTGDIIGD) from volunteer sera of RV144 phase III trial. ${ }^{19}$ The initial ADCC antibody response to the V3 epitopes in our study may occur against the founder virus in most of the early HIV-1 infected individuals. However, the later consequence may depend on the efficiency of each individual immune response. If one can control the virus as in LTNP, the ADCC antibody against these epitopes should be detectable for a longer time period. On the other hand, the virus may mutate the $\mathrm{V} 3$ sequence to evade the immune responses ${ }^{20}$ and later ADCC antibody may be further adapted to recognize the coming mutated V3 epitopes. Thus, the ADCC antibody at the non-early phase would not be able to respond to these original V3 epitopes as we previously reported on ADCC epitopes of HIV-1 in asymptomatic infected individuals. ${ }^{12}$ Our finding of peptide 85 (aa 336-350: GTKWNEVLKKVTKKL) as dominant ADCC epitope was also correspondent to the data of Kulkarni et al. ${ }^{15}$ They demonstrated the recognition of novel antigenic ADCC epitope in sera of LTNPs at the C3 region (aa 331-360: CNISEEKWNKTLQRVSEKLKEHFPNKTIKF).

The CD4-bound conformation of Env was recently shown to be a major target of ADCC-mediating antibodies present in the sera of HIV-1-infected individuals. ${ }^{21}$ Prévost et al. reported the influence of the envelope gp120 Phe 43 cavity on HIV-1 sensitivity to ADCC responses. ${ }^{22}$ While residue S375 in the gp120 Phe 43 cavity is well conserved in the majority of group M HIV-1 isolates, CRF01_AE strains have a naturally occurring histidine at this position (H375). They demonstrated that the H375 increases Env propensity to sample the CD4-bound conformation, thus increasing susceptibility of HIV-1 infected cells to ADCC. They raise the intriguing possibility that the presence of His 375 in the circulating CRF01_AE strain in Thailand might have contributed to the efficacy of the trial by spontaneously exposing epitopes recognized by ADCC -mediating antibodies elicited by the RV144 vaccine regimen. Our finding on peptide 92 (aa 364-378: PSGGDLEITMHHF NC) with His 375 emphasized the immunodominant property of this peptide as ADCC epitope since $49.23 \%$ of tested sera showed the ADCC responses.

Tomaras et al. reported that the first anti-HIV-1 antibody was the antibody against gp41 and appeared 13 days after the appearance of plasma virus. ${ }^{23}$ In our study, the common peptides 190 (aa 708-722: LSFQTPSHHQREPDR) and 191 (aa 712-726: TPSHHQREPDRPEGI) which are located in the Kennedy sequence (KS) of cytoplasmic tail (CT) region of gp41 showed the ability to induce ADCC antibody with the total responses of $21.54 \%$ and $27.69 \%$, respectively, of 65 tested sera (Table 4). This confirmed the study of Dimmock et al. on the alternative topological model of CT sequence: external localization. ${ }^{24}$ Moreover, anti-KE (Kennedy epitope) serum that could specifically neutralize HIV in vitro implied the localization of the KE on the outer surface of the virion. ${ }^{25}$ Abacioglu et al. revealed that the KS epitope PDRPEG was a conformational epitope which could induce non-Nt antibody (Chessie 8) binding to HIV-infected cells. ${ }^{26}$ This indicated the property of ADCC antibody inducible of our peptides as we demonstrated in our study.
Identification of ADCC antibodies targeting conserved non-Env proteins such as Gag may reveal more potent ADCC activities. The appearance of HIV-core antigens on the surface of infected cells has been shown for p17 and p24.27,28 Moreover, the monoclonal antibodies (mAbs) to p24-core protein of HIV-1 have been demonstrated to mediate ADCC activity to destroy infected cells. ${ }^{29}$ Our studies on Gag protein further demonstrated that two epitopes of each peptide pools G1 (peptides 3776, 3779), G2 (peptide 3789, 3790) and G4 (peptides 3800, 3802) were identified as being targets of ADCC antibodies from at least $50.00 \%$ of the sera tested (Table 3). Interestingly, all these 6 epitopes could be able to gain the responses from sera of medium- and low-ADCC activities for at least $12 \%$ and $10 \%$, respectively which made the overall responses to the range of $23.08-41.54 \%$ (Table 5). The aa sequences of the 6 potential ADCC epitopes of HIV-1 CRF01_ AE Gag are also shown in Table 5. The common peptides 3776 and 3779 are localized within the p17 (MA, matrix) region while the common peptides 3789,3790 and 3800,3802 are localized within the p24 (CA, capsid) region (Figure 1). Our finding of peptide 3789 (aa 171-190: MFSALSEGATPQD LNMMLNI) was correspondent to that of Grunow et al. ${ }^{29}$ They showed the recognition of p24-ADCC epitope (aa 178-187: GATPQDLNIM) expressed on the HIV-infected T cells by mAbs. Interestingly, peptides 3779, 3800 and 3802 demonstrated the responses to ADCC activity at an almost equal/higher number of sera of medium- and low-ADCC response groups than those of a high-ADCC response group, i.e., $(32 \%, 35 \%$ vs $35 \%)$, (32\%, $45 \%$ vs $30 \%)$ and $(52 \%, 40 \%$ vs $30 \%$ ), respectively. This revealed the important of these peptide sequences as the dominant ADCC epitopes for induction of ADCC responses against Gag peptides of early HIV-1 infected individuals, i.e., $33.85 \%, 35.39 \%$ and $41.54 \%$, respectively, of total 65 tested sera. Genetic data support a major role for the cytoplasmic tail of gp41 and the matrix domain of Gag in Env glycoprotein incorporation. ${ }^{30}$ Both Gag and Env display properties of being associated with lipid rafts at the plasma membrane. Gag-Env interactions affect their co-recruitment to the virological synapse and subsequent early events in the next round of viral replication. The ADCC antibody against epitopes on matrix domain of Gag demonstrated in our study may have an effect on the new coming viral progeny at the Env incorporation process.

In conclusion, although the degree of ADCC antibody responses to the gp120 protein varied from high to low, there were certain potent consensus Env and Gag peptide epitopes that could induce the ADCC antibody responses in a majority of early infected individuals as shown in this study. This information should be useful for further design of the antibody epitope based vaccine. The pre-existing potent antibody induced by the vaccine should be able to limit the transmitted/founder viruses, delay acquisition, control viral replication and prevent the establishment of infection. Since cell-to-cell transmission appears to be more efficient than that of free virion for HIV-1 infection, ${ }^{31}$ the ADCC responses would be a very important mechanism to eliminate the small number of virus-infected cells from an infected partner before the establishment of infection. Although, Nt antibodies have no effect on cell-to-cell transmission of HIV-1, ${ }^{32}$ their responses 
would be very crucial for eliminating free virions that may enter simultaneously with the viral infected cells during viral transmission. This warrants further study whether these ADCC epitopes also act as Nt antibody epitopes. Our studies are limited by the use of peptide/protein pulsed target cells instead of HIV-1 infected cells. The 3-dimentional structure of Env or Gag on the target cell surface may be not the same as those on the infected cells.

\section{Acknowledgement}

The authors gratefully acknowledge the anonymous individuals' sera used in this study. This study was supported by a grant from the Siriraj Research Development Fund (IO R015733018), Faculty of Medicine Siriraj Hospital, Mahidol University. SS was supported by a Siriraj Graduate Scholarship. No conflicts of interest regarding any aspect of this study.

Author's contributions: SA, SS, ST and NH were contributors for performing experiments including collection of data, analysis; TC and PE oversaw the collection of data, analysis and interpretation; WK is the corresponding author and is the main contributor to the design and direction of the study including writing the manuscript.

\section{References}

1. McKinnon JE, Mellors JW, Swindells S. Simplification strategies to reduce antiretroviral drug exposure: progress and prospects. Antivir Ther. 2009; 14:1-12.

2. Rerks-Ngarm S, Pitisuttithum P, Nitayaphan S, Kaewkungwal J, Chiu J, Paris R, et al. Vaccination with ALVAC and AIDSVAX to prevent HIV-1 infection in Thailand. N Engl J Med. 2009;361:2209-20.

3. Ahmad A, Menezes J. Antibody-dependent cellular cytotoxicity in HIV infections. FASEB J. 1996;10:258-66.

4. Forthal DN, Landucci G, Daar ES. Antibody from patients with acute human immunodeficiency virus (HIV) infection inhibits primary strains of HIV type 1 in the presence of natural-killer effector cells. J Virol. 2001; 75:6953-61.

5. Banks ND, Kinsey N, Clements J, Hildreth JE. Sustained antibody -dependent cell-mediated cytotoxicity (ADCC) in SIV-infected macaques correlates with delayed progression to AIDS. AIDS Res Hum Retroviruses. 2002;18:1197-205.

6. Haynes BF, Gilbert PB, McElrath MJ, Zolla-Pazner S, Tomaras GD, Alam $\mathrm{SM}$, et al. Immune-correlates analysis of an HIV-1 vaccine efficacy trial. N Engl J Med. 2012;366:1275-86.

7. Daar ES, Moudgil T, Meyer RD, Ho DD. Transient high levels of viremia in patients with primary human immunodeficiency virus type 1 infection. $\mathrm{N}$ Engl J Med. 1991;324:961-4.

8. Eller MA, Goonetilleke N, Tassaneetrithep B, Eller LA, Costanzo MC, Johnson S, et al. Expansion of inefficient HIV-specific CD8 T cells during acute infection. J Virol. 2016;90:4005-16.

9. McMichael AJ, Borrow P, Tomaras GD, Goonetilleke N, Haynes BF. The immune response during acute HIV-1 infection: clues for vaccine development. Nat Rev Immunol. 2010;10:11-23.

10. Kantakamalakul W, Pattanapanyasat K, Jongrakthaitae S, Assawadarachai V, Ampol S, Sutthent R. A novel EGFP-CEM-NKr flow cytometric method for measuring antibody dependent cell mediated-cytotoxicity (ADCC) activity in HIV-1 infected individuals. J Immunol Methods. 2006;315:1-10.

11. Sreepian A, Srisurapanon S, Horthongkham N, Tunsupasawasdikul S, Kaoriangudom S, Khusmith S, et al. Conserved neutralizing epitopes of HIV type 1 CRF01_AE against primary isolates in long-term nonprogressors. AIDS Res Hum Retroviruses. 2004;20:531-42.

12. Ampol S, Pattanapanyasat K, Sutthent R, Permpikul P, Kantakamalakul W. Comprehensive investigation of common antibody dependent cell mediated cytotoxicity (ADCC) antibody epitopes of HIV-1 CRF01_AE gp120. AIDS Res Hum Retroviruses. 2012;28:1250-8.
13. Hanson DL, Song R, Masciotra S, Hernandez A, Dobbs TL, Parekh BS, et al. Mean recency period for estimation of HIV-1 incidence with the BED -Capture EIA and Bio-Rad avidity in persons diagnosed in the United States with subtype B. PLoS ONE. 2016:11(4): e0152327.

14. Kijak GH, Tovanabutra S, Rerks-Ngarm S, Nitayaphan S, Eamsila C, Kunasol P, et al. Molecular evolution of the HIV-1 Thai epidemic between the time of RV144 immunogen selection to the execution of the vaccine efficacy trial. J Virol. 2013; 87:7265-81.

15. Kulkarni A, Kurle S, Shete A, Ghate M, Godbole S, Madhavi V, et al. Indian long-term non-progressors show broad ADCC responses with preferential recognition of $\mathrm{V} 3$ region of envelope and a region from Tat protein. Front Immunol. 2017;8:5.

16. Zolla-Pazner S, Cardozo T. Structure-function relationships of HIV-1 envelope sequence-variable regions refocus vaccine design. Nat Rev Immunol. 2010;10:527-35.

17. Jiang $\mathrm{X}$, Burke V, Totrov M, Williams C, Cardozo T, Gorny MK, et al. Conserved structural elements in the V3 crown of HIV-1 gp120. Nat Struct Mol Biol. 2010;17:955-61.

18. Liu P, Yates NL, Shen X, Bonsignori M, Moody MA, Liao HX, et al. Infectious virion capture by HIV-1 gp120-specific IgG from RV144 vaccinees. J Virol. 2013;87:7828-36.

19. Montefiori DC, Karnasuta C, Huang Y, Ahmed H, Gilbert P, de Souza, et al. Magnitude and breadth of the neutralizing antibody response in the RV144 and Vax003 HIV-1 vaccine efficacy trials. J Infect Dis. 2012;206: 431-41.

20. Zolla-Pazner S, Edlefsen PT, Rolland M, Kong XP, deCamp A, Gottardo $\mathrm{R}$, et al. Vaccine induced human antibodies specific for the third variable region of HIV-1 gp120 impose immune pressure on infecting viruses. E Bio Medicine. 2014;1:37-45.

21. Veillette M, Coutu M, Richard J, Batraville LA, Dagher O, Bernard N, et al. The HIV-1 gp120 CD4-bound conformation is preferentially targeted by antibody-dependent cellular cytotoxicity-mediating antibodies in sera from HIV-1-infected individuals. J Virol. 2015; 89:545-51.

22. Prévost J, Zoubchenok D, Richard J, Veillette M, Pacheco B, Coutu M, et al. Influence of the envelope gp 120 Phe 43 cavity on HIV-1 sensitivity to antibody-dependent cell-mediated cytotoxicity responses. J Virol. 2017;91(7).

23. Tomaras GD, Yates NL, Liu P, Qin L, Fouda GG, Chavez LL, et al. Initial B-cell responses to transmitted human immunodeficiency virus type 1 : virion-binding immunoglobulin $\mathrm{M}$ ( $\operatorname{IgM})$ and $\operatorname{IgG}$ antibodies followed by plasma anti-gp41 antibodies with ineffective control of initial viremia. J Virol. 2008;82:12449-63.

24. Dimmock NJ. The complex antigenicity of a small external region of the C-terminal tail of the HIV-1 gp41 envelope protein: a lesson in epitope analysis. Rev Med Virol. 2005;15:365-81.

25. Chanh TC, Dreesman GR, Kanda P, Linette GP, Sparrow JT, Ho DD. Induction of anti-HIV neutralizing antibodies by synthetic peptides. EMBO J. 1986;5:3065-71.

26. Abacioglu YH, Fouts TR, Laman JD, Claassen E, Pincus SH, Moore JP, et al. Epitope mapping and topology of baculovirus-expressed HIV-1 gp160 determined with a panel of murine monoclonal antibodies. AIDS Res Hum Retroviruses. 1994;10:371-81.

27. Shang F, Huang H, Revesz K, Chen HC, Herz R, Pinter A. Characterization of monoclonal antibodies against the human immunodeficiency virus matrix protein, p17gag: identification of epitopes exposed at the surfaces of infected cells. J Virol. 1991;65:4798-804.

28. Laurent AG, Krust B, Rey MA, Montagnier L, Hovanessian AG. Cell surface expression of several species of human immunodeficiency virus type 1 major core protein. J Virol. 1989;63:4074-8.

29. Grunow R, Franke L, Hinkula J, Wahren B, Fenyö EM, Jondal M, et al. Monoclonal antibodies to p24-core protein of HIV-1 mediate ADCC and inhibit virus spread in vitro. Clin Diagn Virol. 1995;3:221-31.

30. Checkley MA, Luttge BG, Freed EO. HIV-1 envelope glycoprotein biosynthesis, trafficking, and incorporation. J Mol Biol. 2011;410:582-608.

31. Evans LA, McHugh TM, Stites DP, Levy JA. Differential ability of human immunodeficiency virus isolates to productively infect human cells. J Immunol. 1987;138:3415-8

32. Gupta P, Balachandran R, Ho M, Enrico A, Rinaido C. Cell-to-cell transmission of human immunodeficiency virus type 1 in the presence of azidothymidine and neutralizing antibody. J Virol. 1989;63:2361-5. 